\title{
Collaborative Educational Leadership: The Emergence of Human Interactional Sense-Making Process as a Complex System
}

\author{
AINI-KRISTIINA JÄPPINEN \\ University of Jyväskylä (Finland)
}

\begin{abstract}
The article aims at explicating the emergence of human interactional sense-making process within educational leadership as a complex system. The kind of leadership is understood as a holistic entity called collaborative leadership. There, sense-making emerges across interdependent domains, called attributes of collaborative leadership. The attributes give rise to the complex system. They are suggested to be the very agents, i.e. both the source and the outcome of the synergetic sense-making process. Hence, the agents are not the single persons involved who, however, supply the collective attributes that are modified through human interaction in a holistic way. For studying the emergence process in reality, a long-term development process within an educational executive team was exploited. The team aimed at co-creating novel leadership thinking and working practices for its new unit after a merger of separated schools. The emergent sense-making process was examined through such agent-attributes that were identified as attractors within the complex system. Moreover, it is argued that illuminating the complex system of collaborative leadership, this can help other leadership teams to better understand their own sense-making processes in the increasingly complex settings of today.
\end{abstract}

\section{Introduction}

I will argue in this paper that the complexity approach can provide valuable novel understanding for the kinds of educational issues and systems that consist of many interacting components and undergo constant change both in an autonomous way and in interaction with their environment (Heylighen, 2008). One of these issues is educational leadership. Hence, the paper takes the complexity viewpoint in examining leadership through human interaction when 
acquiring novel understanding of the complex world and co-creating more adequate leadership practices for everyday school life.

In education, the utilization of complexity research is still quite uncommon. Educational research has not really grasped at complexity until the past ten years (e.g. Beabout, 2012; Davis \& Sumara, 2006, 2008; Haggis, 2009; Osberg, Biesta \& Cilliers, 2008). Applying the idea of complexity in educational leadership, such research is even sparser (Fenwick, 2010; Jäppinen, 2012b; McClellan, 2010; Morrison, 2001, 2002). Fortunately, the situation is slowly changing due to the trends emphasizing collaboration within leadership (e.g. Crevani, Lindgren \& Packenforff, 2007; DuFour 2004; Graen, 2007; Gronn, 2002, 2008; Hargreaves \& Fink, 2006; Harris, 2009; Raelin, 2006; Schein, 2010; Slater, 2005) together with other applicable research on complex adaptive and nonlinear dynamical systems (e.g. Goldstein, Hazy \& Lichtenstein, 2010; Guastello, 2009; Guastello, Koopmans \& Pincus, 2009; Hazy, Goldstein \& Lichtenstein, 2007; Lichtenstein, Uhl-Bien, Marion, Seers, Orton \& Schreiber, 2006; Uhl-Bien \& Marion, 2008).

Nevertheless, it seems that stepping on the thin ice of a new paradigm is considered a dangerous act. As Sergiovanni (1996) stated two decades ago, “...imported theories and practices [from management disciplines] ... do not serve our [schools'] real goals. We need to develop our own theories that emerge from and are central to what schools are like..." (p. xiiixiv). When serious attempts have been made to transfer complexity-based findings through the thick walls of schools, it has aroused resistance with alleged threats. Recently, some scholars have warned about problems that arise if complexity studies are implemented as such in education. Warnings not to apply theories coming from inappropriate sources are correct as such (Fenwick, 2010, 2012). However, if we are too frightened, something valuable can be missed.

I now claim that we can avoid the trap and safely employ the idea of complexity in order to better understand educational leadership. I suggest that the answer lies in studying it from the viewpoint of collaborative non-linear human interaction when people aim at making sense of the complexity around them. My ultimate aim is to enhance the dialogue between educational leadership and complexity research and, thus, reduce the unnecessary fear for utilizing appropriate results from other disciplines. Hence, I argue that 'wise' applications and better understanding of complexity science are essential for coping with today's complex world, including education.

The first argument that the complexity approach is adequate is based on the fact that today's educational organizations at all levels have to adapt to the ambiguity arising both from their internal relations and the complexity in their political, social, or economic surroundings in a way they have not experienced ever before (e.g., Beabout, 2012). The second argument is that complexity within organizations themselves is continuously growing. The increasing complexity requires more understanding of the complex human interaction within educational leadership. Accordingly, as Tsoukas and Dooley (2011) concisely crystallize, "only complexity can cope with complexity" (p. 729). Two research questions are now established. (1) Why should human interactional sense-making processes be examined as a complex system in order to understand the two complexities in educational leadership? (2) How can this complex system be investigated?

First, an overview of human interactional sense-making research within the increasingly complex world and in [educational] leadership is provided. Thereafter, the rationale for considering educational leadership as a complex system will be treated. Within this frame, a 
tested model called TenKeys ${ }^{\circledR}$ will be presented, which I have created in order to study educational leadership from the complexity perspective. Finally, an example of a real-life sensemaking process as a complex system within one educational leadership team will be introduced.

\section{Complexity and Human Interactional Sense-Making}

One way to approach the relationship between complexity and educational leadership is to do it through sense-making involved in human interaction. In brief, sense-making is about giving a meaning to unclear experiences when people deal with uncertainty and ambiguity (e.g., Balogun \& Johnson, 2004, 2005; Stigliani \& Ravasi, 2012; Weick, Sutcliffe \& Obstfeld, 2005). However, already this idea includes two related complexity perspectives that should be treated in conjunction with each other: the attempt to understand the increasingly complex world (e.g., Beabout, 2012) and the complexity of the sense-making process itself (Gioia \& Chittipeddi, 1991; Gioia, Thomas, Clark \& Chittipeddi, 1994; Maitlis, 2005; Maitlis \& Lawrence, 2007; Weick et al., 2005). Next, I will treat these two perspectives within a wider organizational leadership framework and, thereafter, exploit the few researches to examine them, in particular, in educational leadership.

The first perspective includes the idea of individuals attempting to interpret and explain their ever-changing environment, i.e. the complexity around (Balogun \& Johnson, 2004, 2005; Liu \& Maitlis, 2012; Maitlis, 2005; Maitlis \& Lawrence, 2007). As Ancona (2012) confirms, sensemaking is a key leadership capability for understanding the complex world (see also Gioia \& Chittipeddi, 1991). Although not using the very concept of complexity, Weick et al. (2005) also connect sense-making to the complexity perspective in stating that "explicit efforts at sensemaking tend to occur when the current state of the world is perceived to be different from the expected state of the world, or when there is no obvious way to engage the world" (p. 409). Moreover, they use many complexity concepts, such as agency, flow, chaos, equivocality, emergence, and transience.

The other perspective deals with the complex process of sense-making itself. As Weick et al. (2005) state, sense-making induces procedural actions. For instance, Klein, Sayam, Faratin and Bar-Yam (2003) suggest interaction and negotiation as the prerequisites for understanding the dynamic collaborative design, i.e. what kinds of meanings are given to diverse issues in human interaction. Weick et al. (2005) further explain how sense-making deals with interplay between action and interpretation rather than evaluation on choice. I consider this interplay as the main reason for causing complexity.

In order to clarify the complex human interaction sense-making process, I will examine it from the aspect of emergence. In complexity science, emergence is often defined as a selftranscending construction, a semi-autonomous set of processes which includes but also transcends its components (Hazy et al., 2007). However, Goldstein (2007), along with other scholars (Hazy \& Silberstang, 2009), argues that emergence cannot be understood through plain self-organization but should be studied in relation to intentional but spontaneous contribution and interaction, as a continual and conscious social process that addresses the multi-level (Hazy, 2008; Panzar, Hazy, McKelvey \& Schwandt, 2007) and multi-temporal dynamics of leadership (Dooley \& Lichtenstein, 2008). Plowman and Duchon (2007) further state that leadership is about an emergent process. They explain how leadership processes occur continuously and how these 
processes change the system and the system's capabilities. I will exploit this understanding in applying the idea of an emergent sense-making process into educational leadership.

\section{Educational Leadership as an Emergent Sense-Making Process}

The overview above indicates that sense-making is a complex process itself that cannot be predicted or controlled within a complex world. Hence, leadership is embedded into complex human interaction as a systemic approach, an "intrinsic property emerging from the complex systems of human interaction"(Hazy et al., 2007, p. 13). I now argue that although the emergence process cannot be predicted, it can be understood and anticipated. To address the first research question, I explore the nature of human interaction within educational leadership as emergent sense-making when aiming at understanding the complexity around. Thereafter, to address the second question, I consider sense-making within educational leadership as a complex system in exploiting a model that I have created.

\section{Educational leadership as a collective sense-making process}

Amongst the sparse educational leadership studies of sense-making in complex human interaction and for understanding these ambiguous non-linear processes within the complex world, I first quote Thomson and Hall (2011). They argue that educational leadership includes a sense-making process particularly within the social and everyday practice (see also Beabout, 2012). Thomson and Hall (2011) criticize 'thingifying' of leadership that labels it as pure nouns (such as transformational, transformative, distributed, flexible, transactional, servant, relational, integrative, generative, or adaptive) along with diverse specifying adjectives. In their criticism, Thomson and Hall highlight other crucial sides of leadership that are excluded if only nouns and adjectives are used: leadership related to agency, context, and actions (see also van Oord, 2013). Thomson and Hall (2011) further state that people construct meaning out of what they do in order to reduce and redress surprise. Although not using the very concept of complexity, Thomson and Hall touch upon it in speaking about change in relation to educational leadership and asking after how it actually works as a social practice. They also argue that sense-making might be the missing link between the definitions of leadership and the everyday change of leaders' work.

However, 'thingifying' of [educational] leadership is understandable; it is an attempt to explain a phenomenon that cannot, in reality, be thoroughly explained and defined (Grint, 2005). Therefore, I will explain educational leadership by means of the concept of collaborative, along with its derivatives. The concept of collaborative has one advantage: Albeit being a noun, it includes both the agency as ' $\mathrm{co}^{\prime}$ and the action as 'labour', embedded in 'thingifying'. The context-side, emphasized by Thomson and Hall (2011), will be later treated in introducing an ideal model for studying real-life sense-making within human interaction.

Beabout (2102) says that learning through interaction is the central element for understanding educational complexity. This collective learning heavily relates to the sensemaking process as social construction (Maitlis, 2005), found also amongst educational leadership. The increasingly widespread view of education as a shared learning action has strongly contributed to the discovery of complexity science's adaptability to educational endeavors. Fundamental works in this field include The Fifth Discipline by Peter Senge and colleagues (1990), and Self-efficacy: The Exercise of Control by Albert Bandura (1997), where he 
addressed collective efficacy and collaboration as a power for an organization's success. Consequently, many scholars have started to consider educational leadership as a shared activity, called, for instance, distributed leadership (e.g. Gronn, 2002, 2008; Harris 2009; MacBeath, 2005; Spillane, 2006). Despite having different roots and not including the main ideas of complexity science, distributed leadership can be regarded as one important step towards applying the notion of complex systems in educational research. However, there is also an ongoing discussion on what it actually has to offer (e.g. Crawford, 2012; Fenwick, 2012; Lakomski, 2005, 2008) - whether it can provide elements for a strong theoretical framework or is it just a matter of 'The Emperor's New Clothes.' Along with distributed leadership studies, many other researchers have investigated educational leadership as a co-performance. For instance, DuFour (2004), Fullan (2006) and Hargreaves and Fink (2006) have considered leadership as a matter of everybody in an educational community. Further, Slater (2005) calls for collaboration within educational leadership; she even uses the term collaborative leadership, however, without giving an exact definition for the concept.

Nevertheless, the importance of sharing seemed not to be enough in order to apply the complexity approach onto educational leadership. Also the idea of an emergent process proved to be essential. It relates the permanent change in organizational life (Tsoukas \& Chia, 2002) to complex human interaction. For instance, van Oord (2013) suggests that educational leadership should be viewed as a critical and collaborative process. Also Hall and Hord (2001), in considering the nature of the educational change, emphasize the process perspective in all educational endeavours. Moreover, Gioia and others (1994) have studied change in academic education. They consider sense-making as one central element of the collective process. Consequently, I have adopted the idea of an emergent sense-making process in explaining collaborative educational leadership from the complexity perspective.

\section{Educational leadership as an emergent collective property}

As we see from above, educational leadership is increasingly considered as a process where common endeavors play a central role. The main idea is that leadership can be carried out by any member in an organization; it does not belong only to the so-called leaders (Harris, 2009). This kind of point of view then inevitably leads towards a complexity approach. One of the most comprehensive complexity presentations in educational leadership comes from Keith Morrison in School Leadership and Complexity Theory (2002), alongside with some other single innovative works (McClelland, 2010; Morrison, 2001). However, in most educational leadership studies that aim at touching upon its complex and emergent side, leadership is still seen from a hierarchical point of view, even if trying to avoid heroic or leader-follower aspects (Rubin, 2009, Crawford, 2012).

In sum, despite the growing understanding and attempts to explain educational leadership as a shared endeavor and emergent process, many theoretical and most of the hitherto rarer empirical complexity-related studies are still characterized by a leader-centered point of view. Although they describe leadership as a common and complex endeavor, they assume and place the emphasis, in one way or another, on the school leaders themselves (e.g., Lotrecchiano, 2010). Slater (2005), for instance, emphasizes leadership as an emergent process but still considers leadership merely from the point of view of individual leaders. I now argue that the individual-emphasized dimension highly restricts the understanding of educational 
leadership as a complex system. Therefore, I will introduce an ideal model of collaborative leadership in attempting to detach from this more or less narrow perspective.

\section{EDUCATIONAL LEADERSHIP AS A COMPLEX SYSTEM}

Although the studies mentioned above were pivotal in better understanding the shared aspect of educational leadership, they did not seem to provide enough building blocks for the enigmatic process that engenders educational leadership, particularly from the collaborative and heterarchical viewpoint. This lack then led me towards an attempt to understand educational leadership as a non-linear emergent phenomenon, called collaborative leadership. Next, I will introduce an ideal model to investigate educational leadership as a complex and collaborative emerging sense-making process in real-life settings.

The ideal TenKeys ${ }^{\circledR}$ model for understanding the complexity within educational leadership

If educational leadership is understood as a collective property, collaboration inevitably happens across its interdependent domains (Bruns, 2013). In the TenKeys ${ }^{\circledR}$ model, these collective and interdependent domains are called attributes. So far, ten attributes of collaborative leadership are identified: polyphony (Pol), interaction (Int), expertise (Exp), flexibility (Fle), commitment (Com), responsibility (Res), decision-making (Dec), negotiation (Neg), confidencebased control (Con) and self-evaluation (Eva). Moreover, the model includes several explicative nuances, seen in brief in the petals of the 'flower' (Figure 1). They assist in amplifying the sensemaking process in detail, as we will later see in the Result section. The model is an ideal that cannot be ever reached totally in reality. However, it provides both a theoretical framework for better understanding the human interaction process and a practical tool against which the emergent collaborative leadership can be reflected in real-life. 


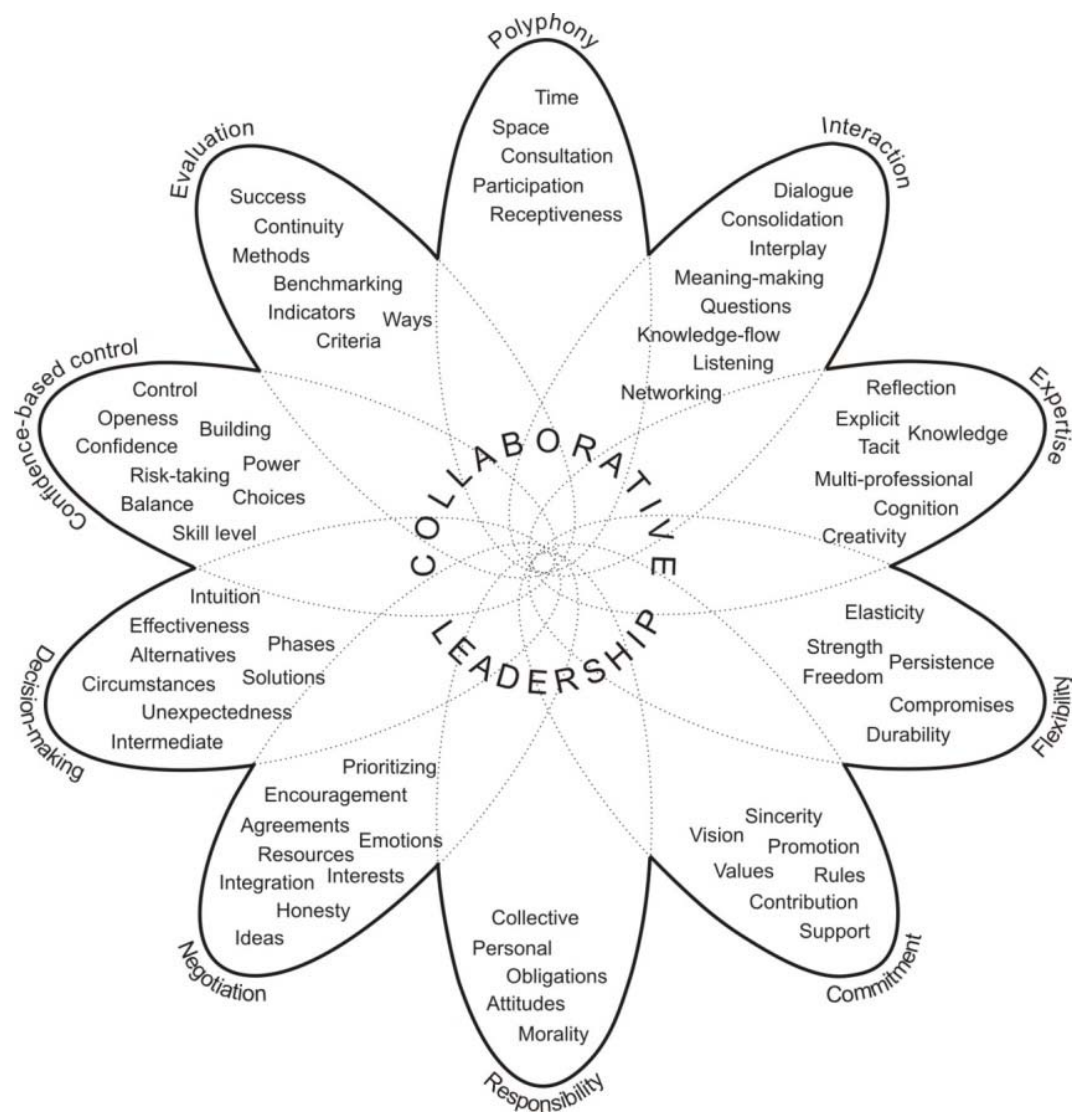

Figure 1. The ideal model of collaborative leadership

The design and development of the ideal model has taken several years, including theory- and data-driven qualitative and quantitative analyses (Jäppinen \& Maunonen-Eskelinen, 2012; Creswell \& Plano-Clark, 2011; Qualitative data analysis, online). The attributes and their nuances have been identified on the basis of two main sources. First, I have drawn on a comprehensive array of leadership theories and studies from different scholars using various synergetic terms, such as flexible, relational, distributed, shared, integrative, dispersed, or generative leadership (e.g., Goldstein, et al., 2010; Hazy, et al., 2007; Graen, 2007; Grint, 2005; Gronn, 2008; Harris, 2009; MacBeath, 2005; Raelin, 2005, 2006; Spillane, 2006; Uhl-Bien \& Marion, 2008). The second source consisted of the results of collaborative leadership features in two large-scale nation-wide studies (Jäppinen, 2012a).

As Goldstein (2007) puts it, the novel order arises out of the interaction of elements of the system. The attributes of the model form a complex system; they are both distinct and connected (Heylighen, 2008). They are distinct in the sense that their number and placement are not fixed. Their 'rough' description is purposely mutable and can be re-modified if new attributes or nuances are found. But the attributes are also connected to each other when they continuously interact in an unpredictable way. They form a complex system, since a change in any of them through human interaction affects not only all the other attributes but the whole system and vice versa. This means that the emergence process cannot be predicted in advance. In other words, the emerging human interaction (Jennings \& Dooley, 2007) gives rise to new forms of collaborative leadership. 
My idea of collaborative leadership is closely connected to the 'duality of structure' suggested by Giddens (1984) (see also Panzar et al., 2007). In the ideal model, duality means that the structural properties of social systems, such as attributes of collaborative leadership, are both a medium and an outcome of the ideas and practices they are recursively producing. It is a circular cause-and-effect feedback system (Heylighen, 2008; Stacey, 1995) where the attributes serve as the fuel that are modified during the emergence process into new outcomes, which in turn will serve as a source to engender new ones. Ultimately, there is a quest for cognitive, social, and emotional synergy creation (Hutchins, 1995; Surowiecki, 2004).

The interdependence of the attributes as a complex system was statistically and empirically tested in two large-scale consecutive nation-wide studies. An executive team of five representatives within a wide range of educational organizations evaluated their state of collaborative leadership through 45 statements. Each of the statements included an attributepair in a random order. For the statistical analyses, nine new groups were formed where each attribute's couplings with all the other attributes were included. The values of Cronbach's Alpha varied between 0.890 and 0.950 . These extremely high values indicated a strong inner validity of the model and high interdependence between the attributes.

\section{Attributes as agents}

The prefix " $\mathrm{co}^{\prime}$ in collaborative leadership means that the emergence is mediated by a collective, such as an organization, team, or any particular group of people, induced through human interaction and yielding sense-making in a series of events (Lichtenstein, et al., 2006). The emergence is due to the complex interaction of the collective attributes. Hence, collaborative leadership is not ultimately about individual agents, such as leaders or followers although they are naturally the main actors in human interaction.

When considering collaborative educational leadership through the idea of changing and varying attributes, this means that the attributes should be considered as the very agents (Anderson, 1999; Stacey, 1995) of the complex system, not the individual participants, albeit being the mediators of the emergent process. As Hazy, Millhiser and Solow (2007) state, 'agents' should be interpreted in the broadest sense and might represent various issues, such as people, ideas, individual decisions, or events. Thus, my model of the complex system of collaborative leadership differs fundamentally from many other complexity-based models. The agents do not refer to the persons involved in; though the persons enable the process through human interaction. The attributes as interactive agents continuously engender new collaborative leadership as both the source and the outcome of the non-linear system.

\section{Method}

\section{Research design and the data}

In order to understand how the ideal model can be applied in practice, I will exploit a real-life human interactional sense-making process within an educational organization of which the name or the original country is not revealed in order to maintain anonymity. This organization was recently incorporated from two previously separate schools into a larger organization of more than 4000 students and 500 staff members. At the same time, new plans were underway to bring several other education institutes in the region under one umbrella organization. 
Meanwhile, the particular educational organization got a new dean, who formed a matrix organization including five new units. All of these complexity issues around challenged educational leadership in the organization. Accordingly, within one of the new units, an especially innovative development process started, initiated by the unit leader and his executive team of 12 members. There were both men and women in the team, and their ages ranged from 35 to 60 . The members represented diverse organizational levels and sectors, such as leadership, management, administration, and teaching. The whole process took 18 months including a preparatory meeting that was not recorded.

The development process aimed at engendering a novel pedagogical collaborative leadership and working culture for their new unit. The executive team was looking for new and creative insights for its leadership practices and organizational strategies to interact successfully within the new setting and respond to the increasing challenges coming from the turbulent world of work as the global financial crisis since 2008 was shattering local economies around the world. Consequently, this initiative provided another complexity source for the new unit along with the organizational merger.

The data consisted of over 10 hours of recorded and transcribed (45 single-spaced pages) freely flowing discussions of the executive team in three developmental whole-day events. The author, assisted by a colleague, observed and recorded the discussions without being involved in the process. The data was in the participants' mother tongue and was translated into English by language experts. Moreover, at the same time, similar data was gathered from several teacher teams that had the same kinds of development days. However, this data is not introduced in this paper.

\section{The analytical process}

From the extended human interaction data, attributes of collaborative leadership were searched for according to the TenKeys ${ }^{\circledR}$ model by means of a qualitative analysis (Qualitative data analysis, online). This was done after individual remarks were screened in order to treat the data as a continuing series of a collective voice. The unit of analysis was a meaningful utterance, ranging from a few words up to several sentences. Whenever an utterance corresponding to an attribute was detected from the data, it was coded to this particular group. The nuances helped to find an appropriate attribute-agent (Figure 1). A part of this data analysis was triangulated by research colleagues. Hence, some data was left aside without references to any of the attributes. The new selected human interactional sense-making data included codes of the attributes and was examined by means of two units of analysis: episodes and events.

In measuring the interaction amongst agents, here the attributes, some scholars use the concept of episode (Lichtenstein et al., 2006). I will use this unit of analysis in the sense that one episode is the collection of all coded communicative extracts as to one development day, numbered and circled from 1 to 3 (Figure 2). The second unit of analysis, the event, is here defined as diverse expressed opinions within these episodes (Lichtenstein et al., 2006). It is important to notice that the events do not correspond to a comprehensive opinion from a particular individual. Due to the understanding of an attribute as the very agent, not an individual, the events can be parts of the sayings of one person or combinations from several persons. They are not necessarily presented in chronological order, either. Nevertheless, the 
events are not in focus in this paper. They are only exploited in providing examples of the complex process of collaborative sense-making.

\section{Results}

I will concentrate here on attractor-attributes (Guastello \& Liebovitch, 2009) and demonstrate their emergence within the sense-making process. The attractor-attributes were identified while establishing attribute networks for each episode. In Figure 2, these complex systems of human interaction sense-making are highlighted by the arrows. In each episode, the arrows start from the first attribute found and coded from the data and finish with the last.

The four illustrations in each episode (Figure 2) indicate four common types of collaborative sense-making process; the other types were less descriptive for the aims of this paper. In general, the most common types referred to how to strengthen the organization in adding in the members' agency and ownership (type 1); how to consolidate the organization's past, present, and future into a coherent whole (type 2); how to elastically yield to the realities of school and social life (type 3); and how to cross inhibitory organizational boundaries at different levels of concepts, relations, and actions (type 4). However, the results from the four types are here treated as an entity in order to give the readers a more comprehensive idea of the complex system of the collaborative leadership sense-making process.

The attractors in the complex system of the sense-making process were identified while calculating the frequencies of the coded attribute manifestations, i.e., the events, from each episode and type, and choosing the most frequent ones as attractor-agents, as compared to the other frequencies within the same episode or type. Hence, the attractors' frequencies are not comparable across different episodes and types. In total, the four types of sense-making processes resulted in 320 events (Table 1). The attractors' frequencies, in total 204 events, taken from the Figure 2, are shown in Table 1 in bold; the other frequencies are put into parentheses.

Next, I will uncover the complex system of collaborative sense-making process within the particular executive team by means of the attribute-attractors. The aim is not to present the entire process due to the limited writing space, but highlight the process from two specific viewpoints: (1) the most common attractor-agents used in the emergence process and (2) the attractor-agents exploited in particular phases of the process.

\section{Episode 1}

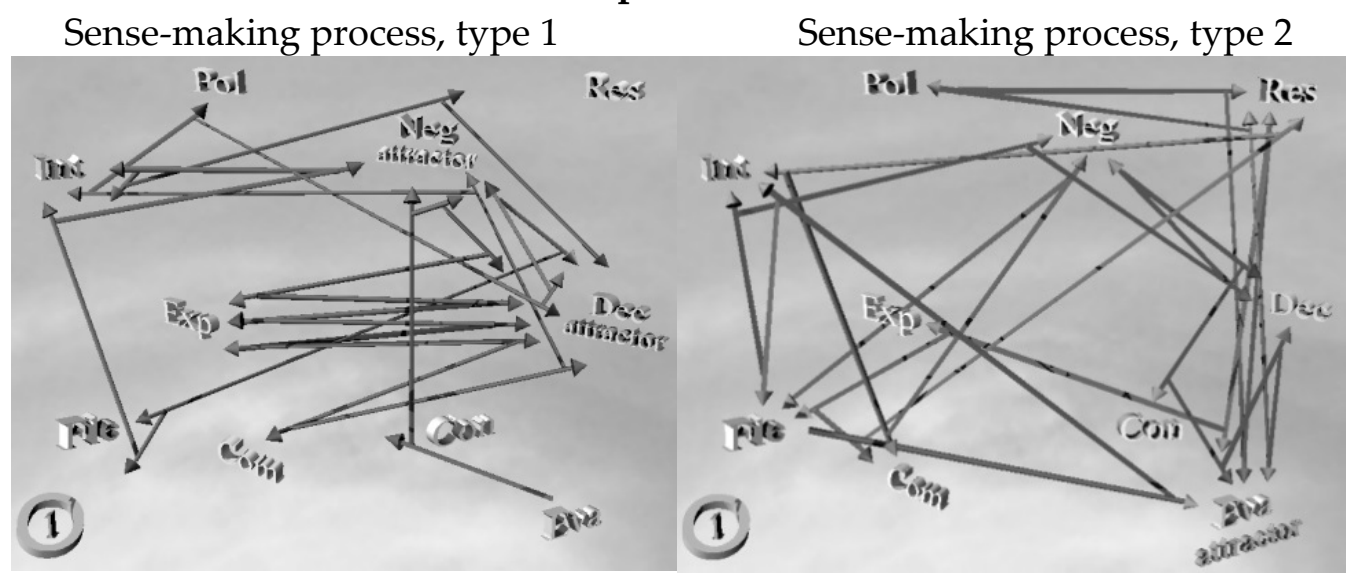


Sense-making process, type 3

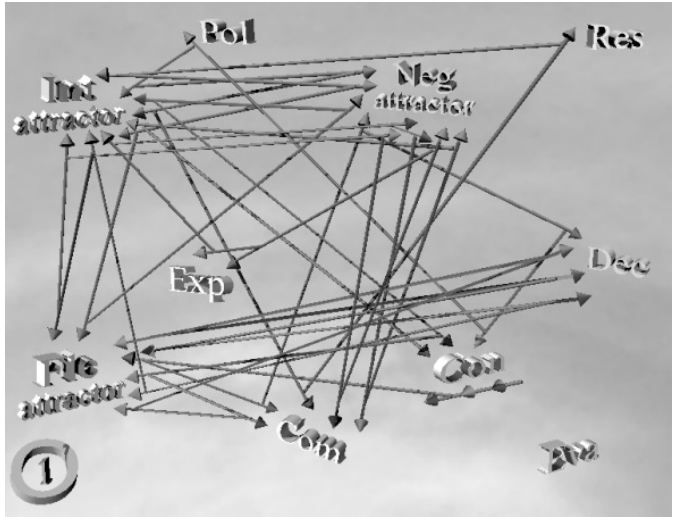

Sense-making process, type 4

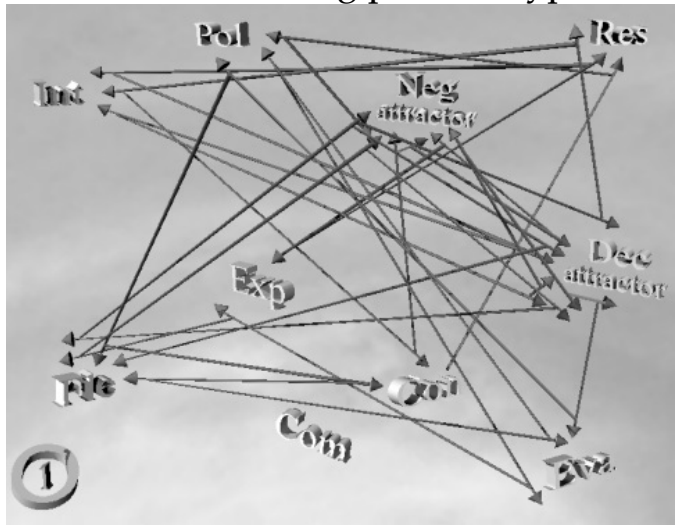

Episode 2

Sense-making process, type 1
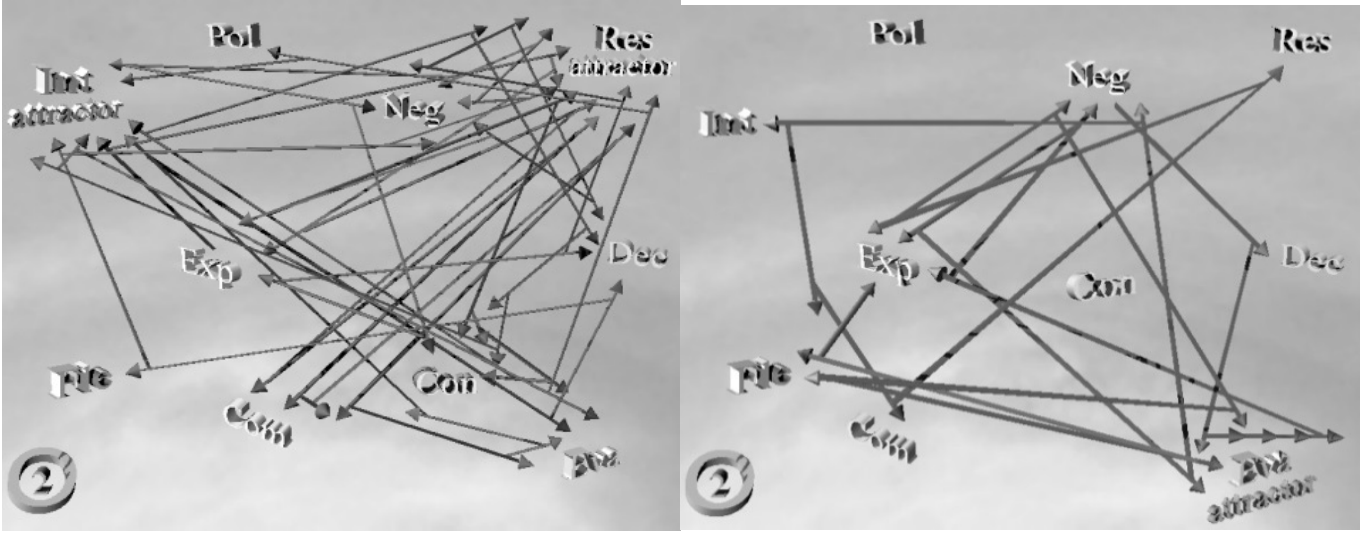

Sense-making process, type 3

Sense-making process, type 4
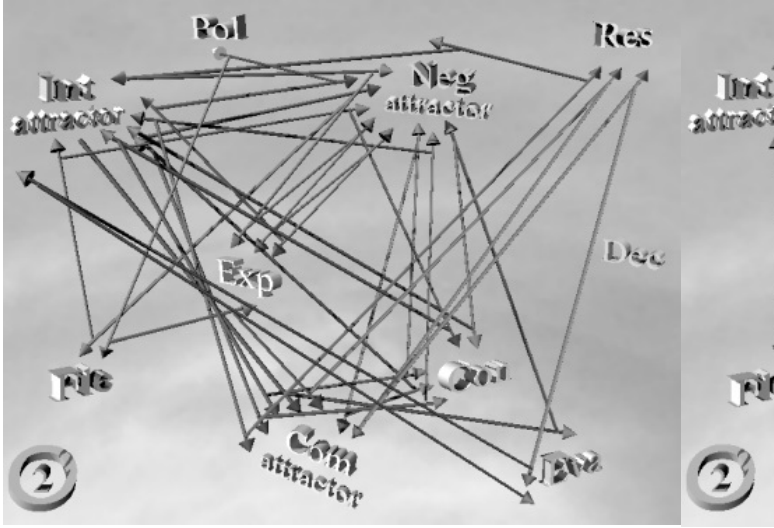

IRtos

Episode 3 

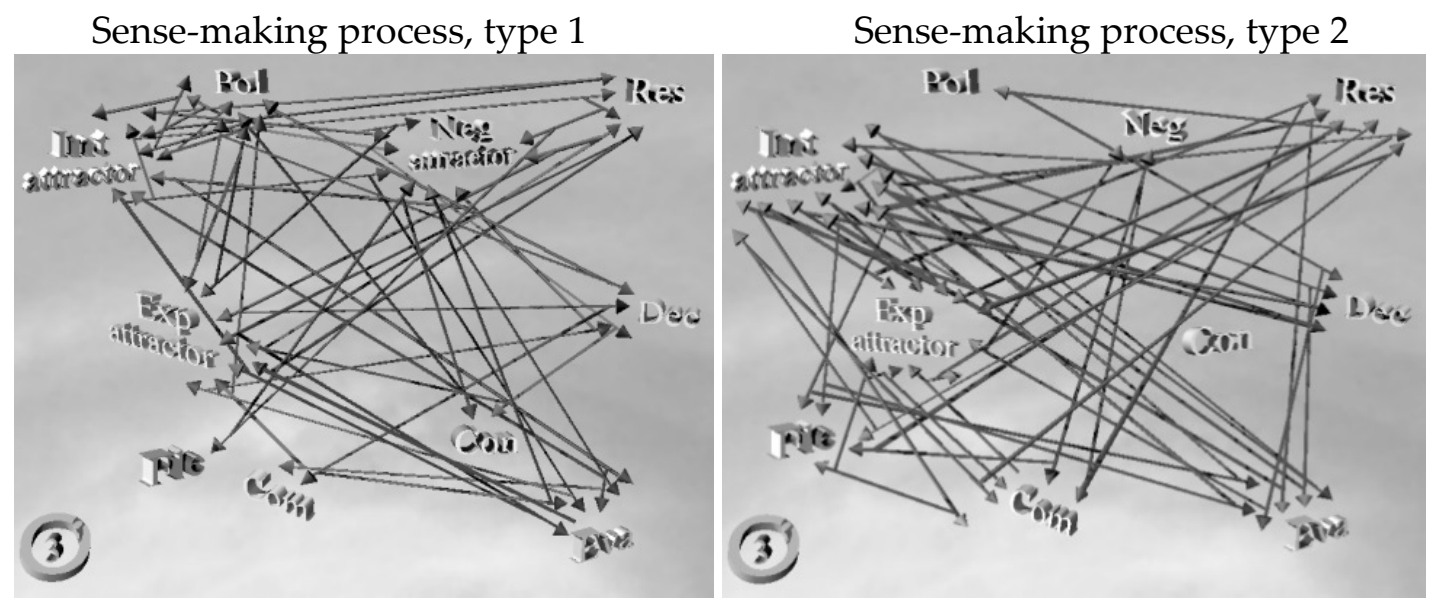

Sense-making process, type 3
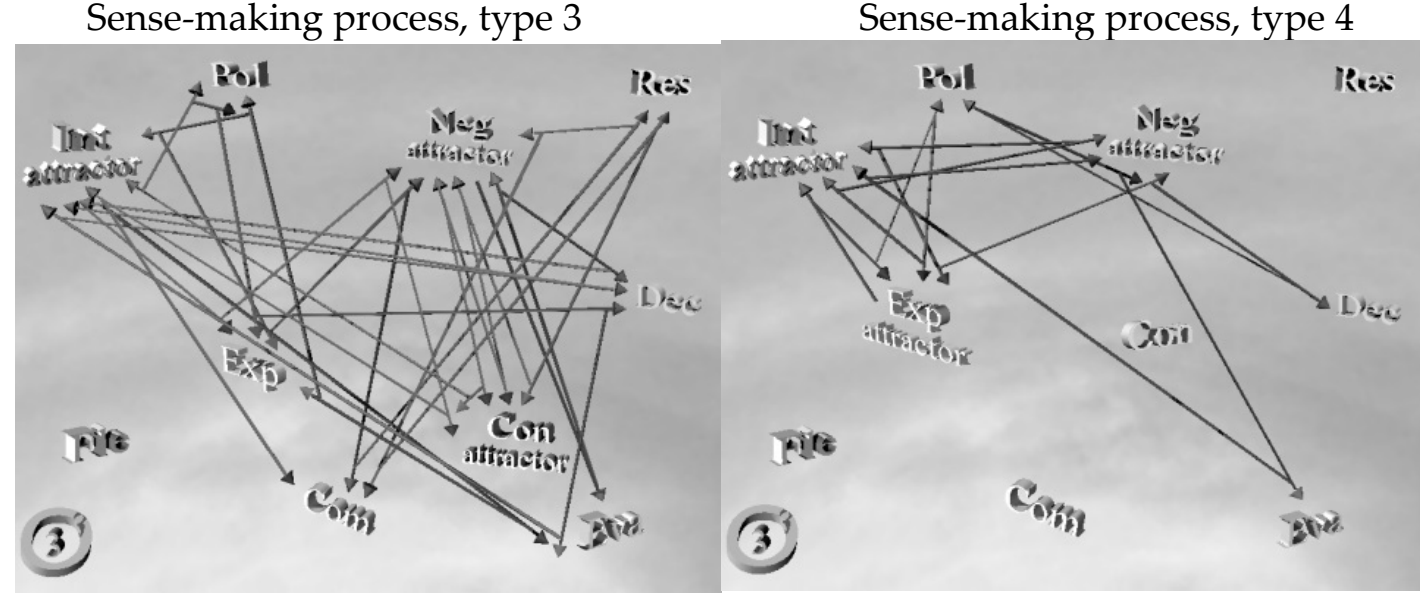

Figure 2. The complex system of human interaction sense-making

Two attribute-attractors manifested throughout the sense-making process. They were negotiation and interaction (Table 2). These attributes seemed to be the foundational building blocks in order to co-create synergy and build up collaborative leadership. The result also resonates with the author's observations and field notes. As regards interaction, it was easy for the members of the executive team to consolidate their different opinions and enter into the dialogue. They were good in meaning-making and presenting significant and critical questions.

Table 1. Frequencies of the coded events in the four types of the sense-making process

\begin{tabular}{|c|c|c|c|}
\hline Attributes & Episode 1 & Episode 2 & Episode 3 \\
\hline \multirow[b]{4}{*}{ Polyphony } & Sensemaking & Sensemaking & Sensemaking \\
\hline & Types & Types & Types \\
\hline & 1. 2. 3. 4. & 1. 2. 3. 4 . & 1. 2. 3. 4. \\
\hline & $(1)(1)(1)(3)$ & $(1)(0)(1) 7$ & $(7)(1)(3)(2)$ \\
\hline Interaction & (4) (3) 9 (3) & $\begin{array}{llll}8 & (1) & 8 & 6\end{array}$ & $\begin{array}{llll}9 & 14 & 6 & 4\end{array}$ \\
\hline Expertise & $(3)(1)(2)(1)$ & (3) (4) (4) (1) & $\begin{array}{llll}9 & 10 & (4) & 4\end{array}$ \\
\hline
\end{tabular}




\begin{tabular}{|c|c|c|c|}
\hline Flexibility & (2) (4) 8 (5) & (1) (3) (2) (1) & (1) (5) (0) (0) \\
\hline Commitment & $(0)(0)(5)(0)$ & (4) (1) $7 \quad$ (1) & $(6)(6)(3)(0)$ \\
\hline Responsibility & $(0)(4)(1)(3)$ & 12 (1) (3) (0) & $(5)(6)(2)(0)$ \\
\hline Negotiation & 6 (3) 96 & (6) (4) 95 & $\begin{array}{llll}9 & (2) & 7 & 4\end{array}$ \\
\hline Decision-making & 9 (3) (4) 9 & $(4)(1)(0)(0)$ & $(4)(4)(3)(1)$ \\
\hline Confidence-based & & & \\
\hline control & $(0)(1)(6)(3)$ & (6) (0) (5) (0) & (6) (0) 5 (0) \\
\hline Evaluation & $(0) 5 \quad(0)(3)$ & (5) 8 (3) (0) & $(7)(6)(3)(1)$ \\
\hline
\end{tabular}

Table 2. The most common attractor-attributes

\begin{tabular}{|c|c|c|c|c|c|c|c|}
\hline Attractor-attributes & \multicolumn{2}{|c|}{ Episode 1} & \multicolumn{3}{|c|}{ Episode 2} & \multicolumn{2}{|c|}{ Episode 3} \\
\hline \multirow[b]{4}{*}{ Negotiation } & \multirow{2}{*}{\multicolumn{2}{|c|}{ Sensemaking }} & \multicolumn{3}{|c|}{ Sensemakino } & \multicolumn{2}{|c|}{ Sensemaking } \\
\hline & & & Typ & & & Types & \\
\hline & 1. 2 . & 3. 4. & 1. & 3 & 4. & 1. 2. & 3. 4 . \\
\hline & & 6 & & 9 & 5 & 9 & 7 \\
\hline Interaction & & 9 & 8 & 8 & 6 & 14 & \\
\hline Expertise & & & & & & 910 & 4 \\
\hline Decision-making & 9 & 9 & & & & & \\
\hline Evaluation & 5 & & & & & & \\
\hline Responsibility & & & 12 & & & & \\
\hline Flexibility & & 8 & & & & & \\
\hline Polyphony & & & & & 7 & & \\
\hline Confidence-based & & & & & & & \\
\hline control & & & & & & & 5 \\
\hline
\end{tabular}

They also knew how to handle contradictions and resolve conflicts, being active listeners (Figure 1). The events below illustrate the use of the interaction-attractor.

Episode 1:

"As those things aren't given to me handed out from above (from the administration), but we prepared them together. I'm sure it would just as well work in student-teacher situations as between leaders, leadership group and the personnel."

"Instead, they (the difficult things) need to be discussed and made sure that we have enough understanding of the matter...Does the model of acting together always has to be a meeting? Or could it be something else?"

"I could imagine that the change needs to be further discussed and the people need to be brought to a point of realization through discussion. Or you yourself have to realize something, for example, that this is how we do it and this can bring about a change."

Episode 2:

"We have been using that [communicative] tool...it has been prepared by the government office. We laughed to that a little, [but] it has been newly tested. It works. This came up with us as we were dividing that [teacher] team: There should be someone available in that discussion, someone who could facilitate." 
"[The teachers] are merely not used to work together. You don't have to pay anything extra for that...the dialogue in that working community, what comes to everyday encounters and standing behind one's words - the problem is so immense. How can creativity be realized? That is what worries me."

\section{Episode 3:}

"Or, then one could develop the opinion with a teacher or a few teachers regarding how this thing could be advanced."

"...A model of co-operational working...We are so early-dinosaur-like and rigid...we send the agenda and that will be discussed. Everyone is sitting quiet and the head teacher talks and a few comments are added to it at some point. In my view, it's not the way it should be. I miss more boldness...I have personally tried that in a teacher meeting, the kind of working model where I haven't planned teacher meetings. I go there to the teacher meeting and everyone gets a piece of paper in front of them. Of course, there are certain things that have to be announced, that's a different matter...the first look of astonishment as I opened the meeting! Everyone could name two things and those were discussed there. It proved to work very well. That meeting had an entirely different atmosphere. What emerges there is that they have been participating."

"There is not that kind of confused state...One can courage them (the teachers) to work together and also to find those solutions so that one doesn't always have to say the answer immediately. Those [answers] will surely be found, let's trust in the own competence and experience of each teacher."

As regards negotiation, the team searched for mutual understanding in prioritizing questions. They took care of the others' emotional needs and were able to make compromises and agreements that benefitted everybody. They were also honest and encouraging towards each other. Finally, they had sufficiently intellectual resources that enabled them to introduce new ideas in combining their different interests (Figure 1). Some examples of the negotiationattractor are seen below in the quotes.

\section{Episode 1:}

"It also has a lot to do with how one perceives leadership and which tasks are given to leaders. Is it to maintain something? It has to do with trust and that one dares to enter different environments emotionally or physically."

"In my view, the common matters of our unit are such things. When you allow it to take place that way around, coming together is fine, but we should be sensitive to what is striving our processes. Things change there...Suddenly something occurs that one needs to comment on."

"Similarly it makes a huge difference how these [teacher] groups meet from the start. It either lifts up the atmosphere or leads it into the other direction. Or then it makes no difference at all to the atmosphere. It makes a huge difference how you put that thing. There are so many ways to formulate the same thing."

\section{Episode 2:}

"I think that we have the exact same situation going on there. I have used a half a day twice with (the name of the person) to discuss it...It was an easy way to proceed with the thing, as we clearly had those matters and even the matter of resources. When you throw it as it is, that anything can be done with this...Something new is created from that and the old got disassembled and something new made space for itself." 
Episode 3:

"In what way do I help teachers to combine real methods? How could I through my own actions somehow cause the things to be stirred...so that they would find it interesting and would become inspired to do it?"

Table 3. The distribution of the attribute-attractors between the three episodes

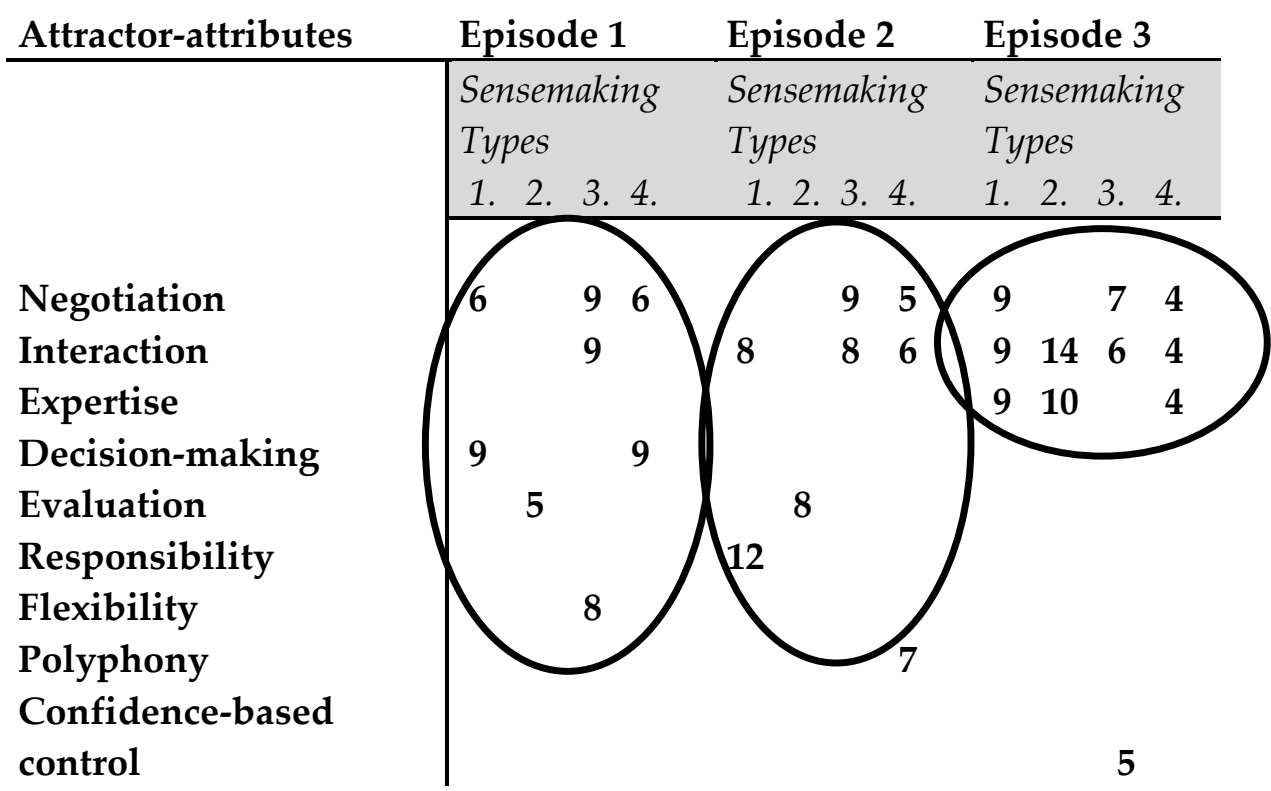

The second viewpoint to examine the results was to find out which attractor-agents the team exploited in different phases of the sense-making process (Table 3, the three circles). The variety of the attributes in the beginning of the process in Episode 1 indicates how the executive team was ready for the change. The team was aiming at detaching from the unnecessary baggage of the old culture of practices and making a breakthrough as to its internal image. This was clearly seen from several events, such as "You need to write down shared rules concerning every odd thing imaginable, how to act... You [should] add a couple of people there who think about what should be done...It takes a lot of time." However, the team also considered how to foster the quality of the new unit. "Courage and changes...some things were always done in a certain way. Is it actually possible to do them a bit differently for once?"

In the second development day a half year later (Episode 2), the attribute-attractors became even more scattered but also sparser (Table 3). This change had a clear reason. In the meantime, the teachers had had their own development days. From a couple of the teacher groups, extremely challenging comments were heard. This negative feedback also altered the emerging sense-making process.

"I personally have been thinking quite a lot about that. What is it in that dynamic that allows teachers to directly offend others through their communication? It takes place quite often. Kind of slightly bring up edges. Building up that co-operation has to be, in my view, based on mutual trust, that is, can we go near to that boundary if it means showing more emotion. In other words, that communication or that culture doesn't rest on a very fair foundation."

During the third development day a couple of months later (Episode 3), the team found out that surprisingly enough, many of the offensive staff members were now implementing new 
ideas and models into their working practices. This was seen as the intensifying and centralized use of the attributes (Table 3). The task of the team became more crystallized and specific.

"We did have this own group of ours where the objective was to reflect and to engage in that dialogue...what we perceive and to which direction we lead this unit together. At this stage, I personally tried hard to do that work but perhaps not enough. Knowing my own team and how they might start to proceed, what has been the procedure in the previous situations and what is good to get accomplished...in that case the foreman is not present there. When the foreman is present, what is the role division at that point? Perhaps it wasn't the right time for a strategy speech. As I see it, the purpose there was to practice that co-operational learning. What I perceived, it came up strongly up... as they (the teachers) were discussing together...I'm thinking about these kinds of observations as we are beginning to proceed with this. They have also discussed different kinds of resources and different things in the groups as we had perhaps originally planned."

For understanding which attractor-agents the team particularly exploited in different phases of the sense-making process, some of them are worth to be presented separately (Table 4, circled). In the beginning (Episode 1) the team largely exploited more 'traditional' attributes, such as decision-making (Table 4). As a collective property of collaborative leadership, decision-making means promoting circumstances which yield productive solutions; supporting multiform thinking and emotional processes; providing sufficient and different alternatives for the decision process; uncovering background or underlying issues; utilizing intuition; linking different phases in the decision-making process onto each other; exploiting unexpected effects; and making necessary intermediate decisions (Figure 1).

"Sometimes attaining a change might require juridical decisions but those matters belong to officials. It is purely a question of law. I don't believe that any of us is able to attain practical changes merely by making decisions. I mean really, given that a real change would occur. Many times when you are talking with a teacher, you lose the track and don't know if we make a decision and what we decide."

Due to the critical teacher voices, the team had to find a new common ground for their collaborative work in the second development-day (Episode 2). For that, they adopted the attribute-attractor of responsibility (Table 4). It includes, for example, collective, personal, moral, and social responsibility; supportive and shared attitudes; high moral standards; approval of jointly agreed-upon practices; finishing one's obligations; proactive attitudes; and

Table 4. The attractor emphases

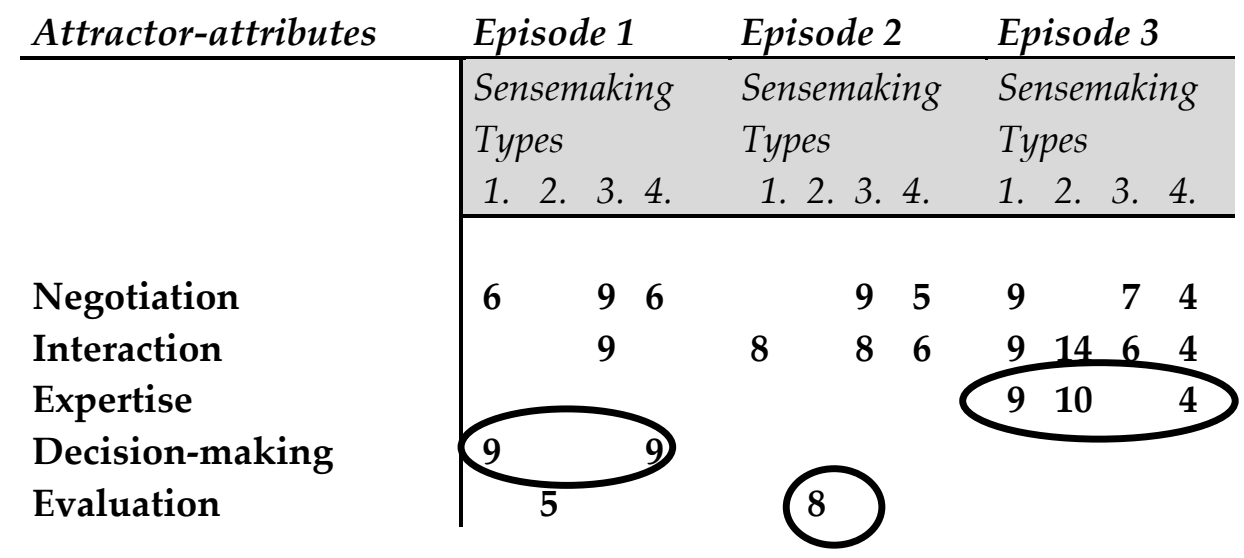




Responsibility
Flexibility
Polyphony
Confidence-based
control

12

8

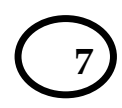

5

long-term activities (Figure 1). This was the only phase where responsibility was exploited as an attractor. In this way, the team wanted to show how they were ready to give the teachers more responsibility for the change process. "Getting more responsibility conveyed to teachers, that is, how to prepare it in such a way that it would be meaningful for both students and themselves."

In the end of the sense-making process (Episode 3), the increasing exploitation of the attribute-attractor of expertise gives evidence that the team had found a more professional grip of the reality in their new unit (Table 4). The attribute of expertise is about distribution of explicit and tacit knowledge; mediation of multi- and inter-professional knowledge; discerning relevant issues; sharing cognition; sharing creativity; and exercising deep reflections (Figure 1). In brief, the emerging process of collaborative leadership had become richer and more diverse. Now, the events were heavily reality-bound and goal-oriented. "...Maintaining that excitement and providing room for it... We have had such a way to proceed...consider the meetings of the school year. It is my habit to hold meetings on Wednesday and Monday mornings so that we have set times. And together with teachers we consider which themes we address and where...I don't know how to hold that kind of a chairman-secretary-meeting...They try to solve and advance things there. Those themes are brought up...Then those next steps towards Christmas, to which direction are we roughly heading, where I am needed and which teachers form that group. They know how to ask help there and then they came up with good ideas. Excellent ideas and then one takes hold of them. Okay, we find time for this and then we note it down so that it won't be forgotten...Then, it is easier to return to it as that everyday busy-ness always tries to pull you down."

Polyphony manifested as an attractor-attribute only once in Episode 2 (Table 4). Polyphony is about consultation of all personnel involved in an issue; wide participation in common endeavors; being receptive to differences and different 'voices' (such as wondering, challenging, agreeing, convincing, asking, doubting etc.); and providing and allowing of space and time for everybody (Figure 1). "In many places there, that kind of discussion is required. It is not those matters, which can merely be announced. It comes to these three-four annual meetings, possible strategies or discussions, possible changes. At present everything gets easily mixed up."

Finally, just in the end of the process in Episode 3, confidence-based control was exploited as an attribute-attractor (Table 4). Confidence-based control increases collaborative strength and capacity and, in this way, maintains openness and sincerity. It builds up skill level, balances power issues and allows a reasonable risk-taking (Figure 1). "[I wish] that leadership would be one practice of this community and not just a process. That people would accept it (the collaborative development of the organization) even more widely if one could consider the matter like this."

\section{Conclusion}

This article aimed at providing novel understanding of educational leadership as a complex non-linear system of human interactional sense-making. However, the complex systems 
involved in educational leadership are not the only complex systems that schools experience. They, being complex systems themselves, act within other complex political, economic, and social systems (Osberg, Biesta \& Cilliers, 2008). This nested complexity puts even greater expectations on the execution of educational leadership for responding to the increasing educational and social demands of today. Hence, I introduced here collaborative leadership both as a theoretical framework and a practical tool for answering the demands. Collaborative leadership encompasses an emergent process when the stakeholders in an educational organization create synergy by means of shared and collective endeavors.

Collaborative leadership was exploited in identifying the human interactional sensemaking process in real-life settings, when a leadership team was confronted with a merger and the consequential complexity in the surroundings and within the very organization. By means of a specific model, I demonstrated how collaborative educational leadership was studied as an emergent sense-making process amongst the team members through collective attributes of agents of the complex system. Some of the attribute-agents proved to be attractors in the sensemaking process. They enabled, in particular, the process as regards the team's ideas, attitude, and practices, and facilitated other necessary adaptations in the new unit.

I argue that if an organization or a team is enabled to comprehend its own non-linear educational leadership processes and its collective attributes, the organization would have better chances to direct its actions so that it will eventually profit all stakeholders in the community, including leaders, administration, teachers, and especially students, in terms of improved learning processes and 'wiser' conducts. This claim was put into practice when a summary of the results was introduced to the particular team. They used it to get an overview of what had really happened within their development process and to further improve the unit.

Finally, I argue that the considerations introduced in this paper about educational leadership as a collaborative and complex endeavor may provide new insights for other organizations and their leadership teams or provide even a survival tool if the organization is exposed to increasing turbulence. In sum, comprehension of one's own emergent collaborative leadership may offer tools for coping better in the middle of the increasing complexity of today.

\section{References}

Ancona, D. (2012). Sensemaking. Framing and acting in unknown. In S. Snook, N. Nohria, \& R. Kuharana (Eds.). The handbook for teaching leadership. Knowing, doing, and being (pp. 3-19). Thousand Okas, CA: Sage.

Anderson, P. (1999). Complexiy theory and organization science. Organization Science, 10, $216-232$.

Balogun, J., \& Johnson, G. (2004). Organizational restructuring and middle manage sensemaking. Academy of Management Journal, 47(4), 523-549.

Balogun, J., \& Johnson, G. (2005). From intended strategies to unintended outcomes: The impact of change recipient sensemaking. Organisation Studies, 26, 1573-1601.

Bandura, A. (1997). Self-efficacy. The exercise of control. New York: W.H. Freeman.

Beabout, B. R. (2012). Turbulence, perturbance, and educational change, Complicity: An International Journal of Complexity and Education, (9)2, 15-29.

Bruns, H. C. (2013). Working alone together: Coordination in collaboration across domains of expertise. Academy of Management Journal, 56(1), 62-83.

Crawford, M. (2012). Solo and distributed leadership: Definitions and dilemmas. Educational Managment Administration E Leadership, 40(5), 610-620.

Creswell, J. W., \& Plano-Clark, V. L. (2011). Designing and conducting mixed methods research. Thousand Oaks, CA: Sage. 
Crevani, L., Lindgren, M., \& Packendorff, J. (2007). Shared leadership: a postheroic perspective on leadership as a collective construction. International Journal of Leadership Studies, 3(1), 40-67.

Davis, B., \& Sumara, D. J. (2006). Complexity and education: Inquiries into learning, teaching, and research. New York, NY: Routledge.

Davis, B., Sumara, D. J. (2008). Complexity as a theory for education. Transactional Curriculum Inquiry, 5(2), 3344.

Dooley, K. J. \& Lichtenstein, B. B. (2008). Research methods for studying the complexity dynamics of leadership. In M. Uhl-Bien, \& R. Marion (Eds.). Complexity leadrship. part I: Conceptual foundation (pp. 269290). Charlotte, NC: Information Age Publishing.

Du Four, R. (2004). What is a "professional learning community"? Educational Leadership, 61(8), 6-11.

Fenwick, T. (2010). Complexity theory, leadership, and the traps of utopia. Complicity: An International Journal of Complexity and Education, 7(2), 90-96.

Fenwick, T. (2012). Complexity science and professional learning for collaboration: A critical reconsideration of possibilities and limitations. Journal of Education and Work, 25(1), 141-162.

Fullan, M. (2006). Leading professional learning. The School Administrator, 63(10), 10-14.

Giddens, A. (1984). The constitution of society. Berkeley, CA: University of California Press.

Gioia, D. A., \& Chittipaddi, K. (1991). Sensemaking and sensegiving in strategic change initiation. Strategic Management Journal, 12, 433-448.

Gioia, D. A., Thomas, J. B., Clark, S. M., \& Chittipaddi, K. (1994). Symbolsim and strategic change in academia: the dynamics of sensemaking and influence. Organization Science, 5(3), 363-383.

Goldstein, J. (2007). A new model for emergence and its leadership implications. In J. K. Hazy, J. Goldstein \& B. B. Lichtenstein (Eds.). Complex systems leadership theory. New perspectives from complexity science on social and organizational effectiveness (pp. 61-92). Mansfield, MA: ISCE Publishing.

Goldstein, J., Hazy, J. K., \& Lichtenstein, B. B. (2010). Complexity and the nexus of leadership: Leveraging nonlinear science to create ecologies of innovation. New York, NY: Palgrave Macmillan.

Graen, G. B. (2007). Asking wrong questions about leadership. American Psychologist, 62(6), 604-605.

Grint, K. (2005). Leadership: Limits and possibilities. New York, NY: Palgrave Macmillan.

Gronn, P. (2002). Distributed leadership as a unit of analysis. The Leadership Quarterly, 13,423-451.

Gronn, P. (2008). The future of distributed leadership. Journal of Educational Administration, 46(2), 141-158.

Guastello, S. J. (2009). Group dynamics. Adaptation, coordination, and the emergence of leaders. In S. J. Guastello, M. Koopmans \& D. Pincus (Eds.). Chaos and complexity in psychology. The theory of non-linear dynamical systems (pp. 402-433). Cambridge: University Press.

Guastello, S. J., Koopmans, M. \& Pincus, D. (2009). Chaos and complexity in psychology. The theory of non-linear dynamical systems (Eds.). Cambridge, MA: University Press.

Guastello, S. J. \& Liebovitch, L. S. (2009). Attractors and chaos. In S. J. Guastello, M. Koopmans \& D. Pincus (Eds.). Chaos and complexity in psychology. The theory of non-linear dynamical systems (pp. 1-40). Cambridge: University Press.

Haggis, T. (2009). Beyond 'mutual constitution': looking at learning and context from the perspective of complexity theory. In R. Edwards, G. Biesta \& M. Thorpe (Eds.). Rethinking contexts for learning and teaching. Communities, activities and networks (pp. 44-60). London: Routledge.

Hall, G. E., Hord, S. M. (2001). Implementing change. Patterns, principles, and potholes. Needham Heights, MA: Allyn and Bacon.

Hargreaves, A. \& Fink, D. (2006). Sustainable leadership. San Francisco, CA: Jossey-Bass.

Harris, A. (2009). Distributed leadership. Different perspective, (Ed.). London: Springer.

Hazy, J. K. (2008). Patterns of leadership. A case study of influence signaling in an entrepreneurial firm. In M. Uhl-Bien, \& R. Marion (Eds.). Complexity leadrship. part I: Conceptual foundation (pp. 379-415). Charlotte, NC: Information Age Publishing.

Hazy, J. K., Goldstein, J., \& Lichtenstein, B. B. (2007). Complex systems leadership theory. New perspectives from complexity science on social and organizational effectiveness (Eds.). Mansfield, MA: ISCE Publishing.

Hazy, J. K., Millhiser, W. P. \& Solow, D. (2007). Mathematical and computational models of leadership: past and future. In J. K. Hazy, J. Goldstein \& B. B. Lichtenstein (Eds.). Complex systems leadership theory. New 
perspectives from complexity science on social and organizational effectiveness (pp. 163-193). Mansfield, MA: ISCE Publishing.

Hazy, J. K., \& Siberstang, J. (2009). Leadership within emergent events in complex systems: Micro-enactments and the mechanism of organisational learning and change. International Journal of Learning and Change, 3(3), 230-247.

Heylighen, F. (2010). Complexity and self-organization. In M. J. Bates, \& M. N. Maack (Eds.). Encyclopedia of library and information sciences (3rd ed). New York, NY: CRC Press. Retrieved from http://pespmc1.vub.ac.be/Papers/ELIS-complexity.pdf

Hutchins, E. (1996). Cognition in the wild. Cambridge, MA: The MIT press.

Jennings, P. L. \& Dooley, K. J. (2007). An emerging complexity paradigm in leadership research. In J. K. Hazy, J. Goldstein \& B. B. Lichtenstein (Eds.). Complex systems leadership theory. New perspectives from complexity science on social and organizational effectiveness (pp. 17-34). Mansfield, MA: ISCE Publishing.

Jäppinen, A.-K. (2012a). Distributed pedagogical leadership in support of student transitions. Improving Schools, 15(1), 23-36.

Jäppinen, A.-K. (2012b). 3D visualization of engendering collaborative leadership in the space. Journal of Systemics, Cybernetics and Informatics, 10(6), 1-7. Retrieved from http://www.iiisci.org/journal/sci/Contents.asp?var=\&previous=ISS1006

Jäppinen, A.-K., \& Maunonen-Eskelinen, I. (2012). Organisational transition challenges in the Finnish vocational education - perspective of distributed pedagogical leadership. Educational Studies, 38(1), 39-50.

Klein, H., Sayama, M., Faratin, P., \& Bar-Yam, Y. (2003). The dynamics of collaborative design: Insights from complex systems and negotiation research. Concurrent Engineering: Research and Applications, 11(3), $201-209$.

Lakomski, G. (2005). Managing without leadership. Amsterdam: Elsevier.

Lakomski, G. (2008). Functionally adequate but causally idle: w(h)ither distributed leadership? Journal of Educational Administration, 46(2), 159-171.

Lichtenstein, B. B., Uhl-Bien, M., Marion, R., Seers, A., Orton, J. D., \& Schreiber, C. (2006). Complexity leadership theory: An interactive perspective on leading in complex adaptive systems. Emergence: Complexity \& Organization, 8(4), 2-12.

Liu, F., \& Maitlis, S. (2014). Emotional dynamics and strategizing processes: A study of strategic conversations in top team meetings. Journal of Management Studies, 51, 202-234.

Lotrecchiano, G. T. (2010). Complexity leadership in transdisciplinary learning environments: A knowledge feedback loop. International Journal of Transdisciplinary Research, 5(1), 29-63.

MacBeath, J. (2005). Leadership as distributed: A matter of practice. School Leadership and Management, 25(4), 349-366.

Maitlis, S. (2005). The social process of organizational sensemaking. Academy of Management Journal, 48(1), 21-49.

Maitlis, S., \& Lawrence, T. B. (2007). Triggers and enables of sensegiving in organizations. Academy of Management Journal, 50(1), 57-84.

McClellan, J. L. (2010). Leadership and complexity: Implications for practice within the advisement leadership bodies at colleges and universities. Complicity: An International Journal of Complexity and Education, 7(2), 3251.

Morrison, K. (2001). Simplicity and complexity in contemporary school leadership: A response to grace. British Journal of Educational Studies 49(4), 379-385.

Morrison, K. (2002). School leadership and complexity theory. London: Routledge.

Osberg, D., Biesta, G. \& Cilliers, P. (2008). From representation to emergence: Complexity's challenge to the epistemology of schooling. Educational Philosophy and Theory, 40(1), 213-227.

Panzar, C., Hazy, J. K., McKelvey, B. \& Schwandt, D. R. (2007). The paradox of complex organizations: Leadership as integrative influence. In J. K. Hazy, J. Goldstein \& B. B. Lichtenstein (Eds.). Complex systems leadership theory. New perspectives from complexity science on social and organizational effectiveness (pp. 305-326). Mansfield, MA: ISCE Publishing.

Plowman, D. a. \& Duchon, D. (2007). Emergent leadership: Getting beyond heroes and scapegoats. In J. K. Hazy, J. Goldstein \& B. B. Lichtenstein (Eds.). Complex systems leadership theory. New perspectives from complexity science on social and organizational effectiveness (pp. 109-127). Mansfield, MA: ISCE Publishing.

Qualitative data analysis. Retrieved from http://www.sagepub.com/upm-data/43454_10.pdf 
Raelin, J. (2005). We the leaders: In order to form a leaderful organization. Journal of Leadership and Organizational Studies, 12(2), 18-30.

Raelin, J. (2006). Does action learning promote collaborative leadership? Academy of Management Learning $\mathcal{E}$ Education, 5(2), 152-168.

Rubin, H. (2009). Collaborative leadership. Developing effective partnerships for communities and schools (2nd ed.). Thousand Oaks, CA: Sage.

Schein, E. H. (2010). Organizational culture and leadership (4th ed.). San Francisco, CA: Jossey-Bass.

Senge, P., Cambron-McCabe, N., Lucas, T., Smith, B., Dutton, J. \& Kleiner, A. (2000). Schools that learn. A fifth discipline fieldbook for educators, parents, and everyone who cares about education. New York: Doubleday.

Sergiovanni, T. J. (1996). Leadership for the schoolhouse. How is it different? Why is it important? San Francisco, CA: Jossey-Bass.

Slater, L. (2005). Leadership for collaboration: an affective process. International Journal of Leadership in Education, $8(4), 321-333$.

Spillane, J. P. (2006). Distributed leadership. San Francisco, CA: Jossey-Bass.

Stacey, R. D. (1995). The science of complexity: An alternative perspective for strategic change processes. Strategic Management Journal, 16(6), 477-495.

Stigliani, I., \& Ravasi, D. (2012). Organizing thoughts and connecting brains: Material practices and the transition from individual to group-level prospective sensemaking. Academy of Management Journal, 55(5), 1232-1259.

Surowiecki, J. (2004). The wisdom of crowds: Why the many are smarter than the few and how collective wisdom shapes business, economies, societes, and nations. New York, NY: Doubleday.

Thomson, P. \& Hall, C. (2011). Sense-making as a lens on everyday change leadership practice: the case of Holly Tree Primary. International Journal of Leadership in Education, 14(4), 385-403.

Tsoukas, H., \& Chia, R. (2002). On organizational becoming: Rethinking organizationalchange. Organization Science, 13(5), 567-82.

Tsoukas, H., \& Dooley, K. J. (2011). Introduction to the special issue: Towards the ecological style: embracing complexity in organizational research. Organization Studies, 32, 729-735.

Uhl-Bien, M., \& Marion, R. (Eds.). (2008). Complexity leadrship. part I: Conceptual foundations. Charlotte, NC: Information Age Publishing.

van Oord, L. (2013). Towards transformative leadership in education. International Journal of Leadership in Education, 16(4), 419-434.

Weick, K. E., Sutcliffe, K. M., \& Obstfeld, D. (2005). Organizing and the process of sensemaking. Organization Science, 16(4), 409-421.

\section{Acknowledgement}

The study was funded by the Academy of Finland.

\section{About the Author}

Professor of Educational Leadership Aini-Kristiina Jäppinen works in the Faculty of Education in the University of Jyväskylä, Finland. Previously, she had a five-year Academy Research Fellow post of the Academy of Finland. Professor Jäppinen's research interests are collaborative leadership, leading educational change through micro-processes and educational leadership considered as a complex system.

(C) Copyright 2014. The author, AINI-KRISTIINA JÄPPINEN, assigns to the University of Alberta and other educational and non-profit institutions a non-exclusive license to use this document for personal use and in courses of instruction provided that the article is used in full and this copyright statement is reproduced. The authors also grant a non-exclusive license to the University of Alberta to publish this document in full on the World Wide Web, and for the document to be published on mirrors on the World Wide Web. Any other usage is prohibited without the express permission of the authors. 